\title{
Effects of oat and rye fractions on biliary and faecal bile acid profiles in Syrian golden hamsters (Mesocricetus auratus)
}

\author{
BY JIE-XIAN ZHANG ${ }^{1,2}$, GÖRAN HALLMANS ${ }^{1,2}$, HERMAN ADLERCREUTZ ${ }^{3}$, \\ PER AMAN ${ }^{4}$, ERIC WESTERLUND ${ }^{4}$, EVA LUNDIN ${ }^{1,2}$ \\ AND ROGER STENLING ${ }^{1,2}$ \\ Departments of ${ }^{1}$ Pathology and ${ }^{2}$ Nutritional Research, University of Umeå, S-901 87 Umeå. Sweden \\ ${ }^{3}$ Department of Clinical Chemistry, University of Helsinki, Meilahti Hospital, SF-00290 Helsinki, \\ Finland \\ ${ }^{4}$ Department of Food Sciences, Swedish University of Agricultural Sciences, S-750 07 Uppsala, \\ Sweden
}

(Received 24 April 1992 - Accepted 9 November 1992)

\begin{abstract}
The effects of bran and starchy endosperm fractions of oat and rye on faecal weight and on biliary and faecal bile acids were studied in Syrian golden hamsters (Mesocricetus auratus). The animals fed on diets supplemented with steam-flaked oat bran, oat bran or rye bran had higher wet and dry weights of faeces compared with the animals fed on the fibre-free or low-fibre endosperm diets. A higher mean percentage of biliary cholic acid and a lower mean percentage of chenodeoxycholic and lithocholic (LCA) acids was observed in the bran-supplemented dietary groups. Animals fed on the bran-supplemented diets had increased daily faecal excretion of both total saponifiable and total free bile acids compared with the animals fed on fibre-free or endosperm-supplemented diets. The mean percentage of total saponifiable bile acids in the faeces was higher, and that of free bile acids lower in the animals fed on bransupplemented diets. A significantly lower concentration of faecal free LCA was observed in the animals fed on the rye-bran diet. Both bran and endosperm diets reduced the faecal LCA:deoxycholic acid compared with the fibre-free diet, but the bran diets had a more pronounced effect than endosperm diets.
\end{abstract}

Oats: Rye: Bile acids: Hamsters

Oat bran is a well-known cereal source of dietary fibre which is rich in partly water-soluble, mixed-linked $\beta$-glucan (Henry, 1987; Shinnick et al. 1988) and possesses hypocholesterolaemic properties both in experimental animals and in humans (Chen \& Anderson, 1981; Gold \& Davidson, 1988; Anderson et al. 1990; Qureshi et al. 1991). The hypocholesterolaemic effect of oats may be related to an increased faecal excretion of bile acids (Judd \& Truswell, 1981; Illman \& Topping, 1985). Since bile acids and their derivatives from bacterial action have been suggested to be a source of carcinogens responsible for colo-rectal cancer (Owen et al. 1987; Nair, 1988), the excessive bile acid excretion induced by oats has aroused the suspicion that oats might play a role in carcinogenesis of the colon (Hurt et al. 1988). For this reason it is of interest to investigate how oats affect bile acid metabolism and the bile acid profile in the faeces.

In most early studies only primary and secondary bile acids have been measured. However, recently it was shown that up to $80 \%$ of the bile acids may occur in the form of a saponifiable fraction (esterified bile acids) and that the degree of esterification depends on the diet (Korpela et al. 1988, 1992). Therefore, we used this new methodology (Korpela et al. 1986) for the present study. 
Untreated oat products may deteriorate during long storage. To keep the products in good condition for a longer time, heat treatment by steam-flaking is commonly performed. Whether the heat treatment interferes with the physiological effects of oats is not clear. Rye has a different dietary fibre composition compared with that of oats, and less is known about its physiological effect.

The aim of the present study was to investigate the effect of oat and rye fractions on the composition of bile acids in bile, on the profile of bile acids in faeces, and to elucidate the possible role that oat and rye fractions may play in bile acid metabolism in the gut.

\section{MATERIALS AND METHODS}

Diets and nutrient analysis

The experimental control diet was a fibre-free diet (FF) prepared from extruded wheat starch, low-fat milk powder (S67; Semper AB, Stockholm, Sweden) and olive oil. The experimental low-fibre diets (LFD) were prepared with the same basic components as those in the FF diet plus starchy endosperm fractions: either heat-treated oat outer endosperm (HOE1), heat-treated oat inner endosperm (HOE2), oat inner endosperm (OE2) or rye endosperm (RE). The experimental high-fibre diets (HFD) were also made with the same basic components as those in the FF diet plus heat-treated oat bran (HOB), oat bran (OB) or rye bran (RB). The fibre content in the LFD was adjusted to $20 \mathrm{~g} / \mathrm{kg}$ and that in the HFD to $120 \mathrm{~g} / \mathrm{kg}$. The procedures for processing and separating oat fractions, oat bran, outer and inner endosperms have been described in detail by Westerlund et al. (1992). The nutrient contents of the oat and rye fractions are listed in Table 1 . The dietary fibre contents of the fractions were analysed by the method described by Theander \& Westerlund (1986) and the mixed-linked $\beta$-glucan content by the method of Åman \& Graham (1987). The crude protein $(\mathrm{N} \times 6.25)$ was analysed by the standard method (Association of Official Analytical Chemists, 1990) and crude fat by the official method of the European Communities (Anon, 1984). All diets were isoenergetic in terms of percentage energy content from the nutrients: $20 \%$ of the energy from protein, $30 \%$ from fat and $50 \%$ from carbohydrates (excluding the energy values contained in dietary fibre and derived from fermentation). Oat fractions were provided by Graminae AB, Lidköping and rye fractions by Wasabröd AB, Filipstad, Sweden. The composition and the nutritional content of the diets are listed in Tables 2 and 3.

\section{Experimental procedures}

Male Syrian golden hamsters (Mesocricetus auratus), 4-6 weeks old (Bamting \& Kingman, Hull, England), were randomized into eight groups, each containing thirteen animals. The animals were individually placed in plastic cages with perforated middle layer and had free access to water and the experimental diets.

After an adaptation for 1 week with conventional laboratory diet (R3-EWOS-ALAB Brood Stock Feed; EWOS AB, Södertälje, Sweden) the hamsters were fed on the experimental diets for 6 weeks. After 4 weeks of feeding the experimental diets the faeces of the individual animals were collected every $24 \mathrm{~h}$ on three consecutive days. Each $24 \mathrm{~h}$ faeces collection was weighed, frozen at $-70^{\circ}$ and freeze-dried before chemical analysis. At the end of the experimental period the animals were anaesthetized with intraperitoneal sodium pentobarbital $(0.03 \mathrm{mg} / \mathrm{g}$ body weight) and a midline laparotomy was performed. After ligation of the common bile duct for $25 \mathrm{~min}$ the gall bladder was removed and the bile in the gall bladder collected. The collected bile samples were frozen at $-70^{\circ}$ and kept frozen until analysed. 
Table 1. Nutrient content of the fractions of oat and rye $(\mathrm{g} / \mathrm{kg})$

\begin{tabular}{|c|c|c|c|c|c|c|c|}
\hline \multirow{2}{*}{$\begin{array}{l}\text { Cereal } \\
\text { fraction }\end{array}$} & \multirow[b]{2}{*}{ Protein } & \multirow[b]{2}{*}{ Fat } & \multirow[b]{2}{*}{ Carbohydrates* } & \multicolumn{2}{|c|}{ Dietary fibre } & \multirow[b]{2}{*}{ Moisture } & \multirow[b]{2}{*}{ Ash } \\
\hline & & & & Total & $\beta$-glucan & & \\
\hline $\mathrm{HOB}$ & 137 & 107 & 396 & 204 & 74 & 122 & 34 \\
\hline HOEl & 87 & 64 & 661 & 52 & 19 & 127 & 10 \\
\hline HOE2 & 80 & 60 & 681 & 41 & 20 & 129 & 9 \\
\hline OB & 143 & 102 & 416 & 197 & 70 & 112 & 34 \\
\hline OE2 & 81 & 62 & 689 & 40 & 18 & 119 & 9 \\
\hline $\mathrm{RB}$ & 123 & 36 & 476 & 198 & 24 & 142 & 25 \\
\hline RE & 45 & 10 & 752 & 45 & 7 & 144 & 4 \\
\hline
\end{tabular}

$\mathrm{HOB}$, heat-treated oat bran; HOE1, HOE2, heat-treated oat outer and inner endosperm respectively; OB, oat bran; OE2, oat inner endosperm; RB, rye bran; RE, rye endosperm.

* Calculated value for carbohydrates excluding dietary fibre.

Table 2. The composition of the experimental diets $(\mathrm{g} / \mathrm{kg})$

\begin{tabular}{lccccccc}
\hline \hline Diet & S67* & Olive oil & Starch & $\begin{array}{l}\text { Vitamin } \\
\text { mixture }\end{array}$ & $\begin{array}{c}\text { Mineral } \\
\text { mixture }\end{array}$ & Gelatin & $\begin{array}{c}\text { Cereal } \\
\text { fraction } \\
\text { added }\end{array}$ \\
\hline HOB & 113 & 49 & 180 & 10 & 50 & 10 & 588 \\
HOE1 & 221 & 104 & 201 & 12 & 60 & 10 & 392 \\
HOE2 & 215 & 99 & 116 & 12 & 60 & 10 & 488 \\
OB & 102 & 50 & 156 & 10 & 50 & 10 & 622 \\
OE2 & 212 & 98 & 108 & 12 & 60 & 10 & 500 \\
RB & 120 & 90 & 114 & 10 & 50 & 10 & 606 \\
RE & 241 & 123 & 110 & 12 & 60 & 10 & 444 \\
FF & 281 & 132 & 505 & 12 & 60 & 10 & 0 \\
\hline \hline
\end{tabular}

$\mathrm{HOB}$, heat-treated oat bran; HOE1, HOE2, heat-treated oat outer and inner endosperm respectively; OB, oat bran; OE2, oat inner endosperm; RB, rye bran; RE, rye endosperm; FF, fibre-free.

* Low-fat milk powder; Semper AB, Sweden.

Table 3. Nutrient and energy contents of the experimental diets

\begin{tabular}{|c|c|c|c|c|c|c|c|c|}
\hline \multirow[b]{2}{*}{ Diet } & \multicolumn{3}{|c|}{ Nutritional content $(\mathrm{g} / \mathrm{kg})$} & \multicolumn{2}{|c|}{ Dietary fibre $(\mathrm{g} / \mathrm{kg})$} & \multicolumn{3}{|c|}{ Energy $(\%)$ from } \\
\hline & Protein & Fat & Carbohydrate* & Total & $\beta$-glucan & Protein & Fat & Carbohydrate* \\
\hline HOB & 165 & 114 & 411 & 120 & 435 & 20.0 & $30 \cdot 0$ & $50 \cdot 0$ \\
\hline HOEl & 191 & 132 & 477 & 20 & 74 & $20 \cdot 0$ & $30 \cdot 1$ & $49 \cdot 9$ \\
\hline HOE2 & 192 & 131 & 475 & 20 & 98 & $20 \cdot 1$ & $30 \cdot 0$ & $49 \cdot 9$ \\
\hline $\mathrm{OB}$ & 166 & 115 & 414 & 120 & 435 & 20.0 & $30 \cdot 1$ & $49 \cdot 9$ \\
\hline OE2 & 191 & 132 & 479 & 20 & 90 & $20 \cdot 0$ & $29 \cdot 9$ & $50-1$ \\
\hline RB & 164 & 114 & 411 & 120 & 145 & $19 \cdot 9$ & $30 \cdot 0$ & $50 \cdot 1$ \\
\hline RE & 190 & 131 & 476 & 20 & 31 & $20 \cdot 0$ & $30 \cdot 0$ & $50 \cdot 0$ \\
\hline FF & 197 & 136 & 494 & 0 & 0 & $20 \cdot 0$ & $30 \cdot 0$ & $50 \cdot 0$ \\
\hline
\end{tabular}

HOB, heat-treated oat bran; HOE1, HOE2, heat-treated oat outer and inner endosperm respectively; OB, oat bran; OE2, oat inner endosperm; RB, rye bran; RE, rye endosperm; FF, fibre-free.

* Calculated value for carbohydrates excluding dietary fibre. 


\section{Chemical analyses of biliary and faecal bile acids}

The total content and composition of bile acids were measured by GLC after alkaline treatment of bile samples with subsequent extraction of free acids according to the method of Bosaeus et al. (1986), followed by preparation of corresponding methyl esters by the method of Shaw \& Elliott (1978). The GLC analyses were performed on a Hewlett Packard 5890 instrument fitted with an auto-injector and an SE-52 column $(25 \mathrm{~m} \times 0.25 \mathrm{~mm}$ i.d., helium flow $1.5 \mathrm{ml} / \mathrm{min}$ ) which was first held at $250^{\circ}$ for $6 \mathrm{~min}$ and then heated to $280^{\circ}$ at a rate of $1.0^{\circ} / \mathrm{min}$. The GLC was calibrated with authentic samples of the bile acids and the internal standards stigmasterol and $5-\beta$-cholanic acid. Calculation of raw data was performed using Model 2600 chromatography software from Nelson Analytical Inc. (Cupertino, CA, USA). The multicomponent analysis of the faecal bile acids was accomplished by the GLC method of Korpela et al. (1988).

\section{Statistics}

Data were expressed as means and standard deviations and subjected to analysis of variance before the evaluations were performed with Student's $t$ test between different groups. Pearson's coefficient of correlation was used for selected variables.

\section{RESULTS \\ Daily excretion of faeces}

Wet and dry weights of faeces excreted daily for the dietary groups supplemented with bran (HOB, OB and RB) were higher than those for the FF dietary group (fibre-free; $P=0 \cdot 000$ ) and the corresponding groups supplemented with oat or rye endosperm (HOE1, HOE2, OE2 and RE; $P=0 \cdot 000$; Table 4). A higher faecal moisture content was observed in the $\mathrm{RB}$ dietary group than in group FF $(P=0.001)$.

\section{Bile acids in the bile}

No significant difference in the concentration of biliary total bile acids was observed between the dietary groups (Table 5). For groups HOB and OB the concentrations of chenodeoxycholic (CDCA), deoxycholic (DCA) and lithocholic (LCA) acids were lower than those for the FF dietary group (HOB group $P=0.006, P=0.033$ and $P=0.004$, respectively; OB group $P=0.007, P=0.022$ and $P=0.003$, respectively), and for the corresponding endosperm-supplemented diets HOE1 (HOB, $P=0.014, P=0.032$ and $P=0.003$ respectively), HOE2 (HOB group, $P=0.001, P=0.002$ and $P=0.000$, respectively) and OE2 (OB group, $P=0.014, P=0.002$ and $P=0.002$, respectively). In the $\mathrm{RB}$ dietary group the CDCA concentration was lower than that for the FF group $(P=0.015)$, and LCA was lower than that for the FF $(P=0.005)$ and RE $(P=0.005)$ groups.

The proportion of biliary cholic acid (CA) relative to total bile acids for the bran groups (HOB, OB and RB) was higher than those for the FF ( $P=0.000$ respectively) and corresponding endosperm (HOE1, HOE2, OE2 and RE) dietary groups $(P=0.000$ respectively) but the proportion of CDCA was lower than that for the FF $(P=0.000$, $P=0.001$ and $P=0.001)$ and corresponding endosperm HOE1 $(P=0.001)$, HOE2 $(P=0.000)$, OE2 $(P=0.023)$ and RE $(P=0.000)$ dietary groups (Table 6). The proportion of biliary LCA relative to total bile acids for the bran groups (OB and RB) was lower than that for the FF dietary group $(P=0.001$ and $P=0.002$, respectively) and those for the corresponding endosperm OE2 $(P=0.021)$ and RE $(P=0.023)$ groups, but for the heattreated oat bran group (HOB) it was only lower than that for the FF dietary group $(P=0 \cdot 017)$. 
Table 4. Effect of oat and rye fractions on wet and dry weight of the faeces in Syrian golden hamsters (Mesocricetus auratus)

(Mean values and standard deviations for thirteen hamsters/group)

\begin{tabular}{|c|c|c|c|c|c|c|}
\hline \multirow{3}{*}{$\begin{array}{l}\text { Dietary } \\
\text { group } \neq\end{array}$} & \multicolumn{6}{|c|}{ Faecal wt (g/d) } \\
\hline & \multicolumn{2}{|c|}{ Wet wt } & \multicolumn{2}{|c|}{ Dry wt } & \multicolumn{2}{|c|}{ Moisture } \\
\hline & Mean & SD & Mean & $\mathrm{SD}$ & Mean & $S D$ \\
\hline $\mathrm{HOB}$ & $0.64^{*}$ & $0 \cdot 10$ & $0.61^{*}$ & $0 \cdot 10$ & 0.03 & 0.01 \\
\hline HOEl & $0.46 \dagger$ & 0.12 & $0.43 \dagger$ & 0.11 & 0.03 & $0-01$ \\
\hline HOE2 & $0 \cdot 41 \dagger$ & 0.07 & $0.38+$ & 0.07 & $0 \cdot 02$ & $0 \cdot 01$ \\
\hline OB & $0.77^{*}$ & 0.09 & $0 \cdot 74^{*}$ & 0.09 & $0 \cdot 03$ & 0.01 \\
\hline $\mathrm{OE} 2$ & $0.48 \dagger$ & $0 \cdot 11$ & $0.45 \dagger$ & $0 \cdot 11$ & $0 \cdot 03$ & 0.02 \\
\hline RB & $0 \cdot 89^{*}$ & $0 \cdot 12$ & $0 \cdot 84^{*}$ & $0 \cdot 13$ & $0.05^{*}$ & 0.03 \\
\hline RE & $0.45 \dagger$ & 0.07 & $0.42 \dagger$ & 0.07 & $0.02 \dagger$ & 0.01 \\
\hline $\mathrm{FF}$ & 0.39 & $0 \cdot 11$ & $0 \cdot 36$ & $0 \cdot 11$ & $0 \cdot 03$ & 0.01 \\
\hline
\end{tabular}

HOB, heat-treated oat bran; HOE1, HOE2, heat-treated oat outer and inner endosperm respectively; OB, oat bran; OE2, oat inner endosperm; RB, rye bran; RE, rye endosperm; FF, fibre-free.

Mean values were significantly different from those for the FF dietary group: ${ }^{*} P<0.05$.

Mean values were significantly different from those for the corresponding bran dietary group: $\dagger P<0.05$.

\$ For details of composition, see Tables 1-3.

Table 5. Effect of oat and rye fractions on the concentration of biliary bile acids in Syrian golden hamsters (Mesocricetus auratus)

(Mean values and standard deviations for thirteen hamsters/group)

\begin{tabular}{|c|c|c|c|c|c|c|c|c|c|c|}
\hline \multirow{3}{*}{$\begin{array}{l}\text { Dietary } \\
\text { group } \neq\end{array}$} & \multicolumn{10}{|c|}{ Concentration of biliary bile acids $(\mathrm{mmol} / \mathrm{l})$} \\
\hline & \multicolumn{2}{|c|}{ Cholic } & \multicolumn{2}{|c|}{ Chenodeoxycholic } & \multicolumn{2}{|c|}{ Deoxycholic } & \multicolumn{2}{|c|}{ Lithocholic } & \multicolumn{2}{|c|}{ Total } \\
\hline & Mean & $\mathrm{SD}$ & Mean & $S D$ & Mean & $S D$ & Mean & $\mathrm{SD}$ & Mean & $\mathrm{SD}$ \\
\hline НOB & $20 \cdot 2$ & 7.6 & $9 \cdot 0^{*}$ & $4 \cdot 3$ & $4 \cdot 7^{*}$ & $2 \cdot 1$ & $0 \cdot 6^{*}$ & $0 \cdot 2$ & $34 \cdot 4$ & $13 \cdot 3$ \\
\hline HOE 1 & $19 \cdot 1$ & $3 \cdot 3$ & $13 \cdot 1 \dagger$ & $3 \cdot 5$ & 6.51 & $2 \cdot 0$ & $0.9 \dagger$ & 0.3 & $39 \cdot 5$ & $6 \cdot 3$ \\
\hline HOE2 & 23.0 & $7 \cdot 1$ & $15 \cdot 7 \dagger$ & $4 \cdot 1$ & $7 \cdot 4 \dagger$ & $2 \cdot 0$ & $1.0 \dagger$ & 0.3 & $47 \cdot 1$ & 11.6 \\
\hline $\mathrm{OB}$ & $22 \cdot 1$ & 4.9 & $9 \cdot 7^{*}$ & 3.0 & $4 \cdot 8^{*}$ & 1.4 & $0.6^{*}$ & 0.2 & $37 \cdot 1$ & $7 \cdot 6$ \\
\hline $\mathrm{OE} 2$ & $23 \cdot 2$ & $5 \cdot 4$ & $15.0 \dagger$ & 6.5 & $7 \cdot 5 \dagger$ & 2.5 & $0.9 \dagger$ & 0.4 & $46 \cdot 7$ & 12.1 \\
\hline RB & 22.5 & 4.8 & $10 \cdot 3^{*}$ & 2.5 & 5.9 & 1.9 & $0.6^{*}$ & 0.1 & $39 \cdot 2$ & 7.0 \\
\hline RE & $18 \cdot 7$ & $6 \cdot 4$ & $13 \cdot 7$ & $4 \cdot 6$ & $6 \cdot 1$ & $2 \cdot 5$ & $1.0 \dagger$ & 0.6 & $39 \cdot 4$ & 12.7 \\
\hline $\mathrm{FF}$ & $19 \cdot 0$ & 5.8 & 14.8 & 6.0 & $6 \cdot 7$ & $2 \cdot 6$ & {$[\cdot 1$} & 0.6 & $42 \cdot 6$ & 13.6 \\
\hline
\end{tabular}

HOB, heat-treated oat bran; HOE1, HOE2, heat-treated oat outer and inner endosperm respectively; OB, oat bran; OE2, oat inner endosperm; RB, rye bran; RE, rye endosperm; FF, fibre-free.

Mean values were significantly different from those for the FF dietary group: ${ }^{*} P<0.05$.

Mean values were significantly different from those for the corresponding bran dietary group : $† P<0.05$.

$\ddagger$ For details of composition, see Tables 1-3.

Bile acids in the faeces

The animals fed on the bran-supplemented diets (HOB, OB and RB) had higher daily excretions of total saponifiable (SpBA), total free (FBA) and, thus, total analysed bile acids (TBA; SpBA + FBA) in faeces compared with those for the animals fed on the FF $(P=0.000$ respectively) and corresponding endosperm-supplemented diets, HOE1 
Table 6. Effect of oat and rye fractions on the amounts of biliary individual bile acid relative to total bile acids and biliary lithocholic $(L C A)$ :deoxycholic $(D C A)$ acid in Syrian golden hamster (Mesocricetus auratus)

(Mean values and standard deviations for thirteen hamsters/group)

\begin{tabular}{|c|c|c|c|c|c|c|c|c|c|c|}
\hline \multirow{3}{*}{$\begin{array}{l}\text { Dietary } \\
\text { group }\end{array}$} & \multicolumn{10}{|c|}{ Amounts biliary individual bile acid ( $\%$ total bile acids) } \\
\hline & \multicolumn{2}{|c|}{ Cholic } & \multicolumn{2}{|c|}{ Chenodeoxycholic } & \multicolumn{2}{|c|}{ Deoxycholic } & \multicolumn{2}{|c|}{ Lithocholic } & \multicolumn{2}{|c|}{ LCA:DCA } \\
\hline & Mean & SD & Mean & $\mathrm{SD}$ & Mean & sd & Mean & SD & Mean & SD \\
\hline HOB & $59 \cdot 1^{*}$ & $3 \cdot 7$ & $25 \cdot 3 *$ & $4 \cdot 8$ & $13 \cdot 8$ & $3 \cdot 7$ & $1 \cdot 8^{*}$ & $0 \cdot 6$ & $0 \cdot 14$ & 0.05 \\
\hline HOEl & $48 \cdot 4 \dagger$ & $5 \cdot 3$ & $32 \cdot 9 \dagger$ & $5 \cdot 6$ & $16 \cdot 5$ & 4.9 & $2 \cdot 2$ & 0.6 & $0 \cdot 14$ & $0 \cdot 04$ \\
\hline HOE2 & $48 \cdot 2 \dagger$ & $4 \cdot 2$ & $33 \cdot 3 \dagger$ & $3 \cdot 4$ & $16 \cdot 2$ & $4 \cdot 3$ & $2 \cdot 3$ & 0.7 & 0.14 & 0.04 \\
\hline OB & $59 \cdot 6^{*}$ & $5 \cdot 6$ & $25 \cdot 9^{*}$ & $5 \cdot 5$ & $13 \cdot 0$ & $3 \cdot 3$ & $1.5^{*}$ & $0 \cdot 3$ & $0 \cdot 12^{*}$ & 0.04 \\
\hline OE2 & $50 \cdot 1 \dagger$ & $5 \cdot 4$ & $31 \cdot 2 \dagger$ & $5 \cdot 1$ & $16 \cdot 6$ & $5 \cdot 4$ & $2 \cdot 1 \dagger$ & $0 \cdot 7$ & 0.13 & 0.03 \\
\hline RB & $57 \cdot 1^{*}$ & $3 \cdot 1$ & $26 \cdot 2^{*}$ & $4 \cdot 5$ & $15 \cdot 2$ & $5 \cdot 1$ & $1.5^{*}$ & 0.4 & $0.11^{*}$ & 0.04 \\
\hline $\mathrm{RE}$ & $47 \cdot 4 \dagger$ & $4 \cdot 2$ & $34.6 \dagger$ & $4 \cdot 7$ & 154 & $3-5$ & $2.6 \dagger$ & 1.5 & $0 \cdot 17 \dagger$ & 0.09 \\
\hline $\mathrm{FF}$ & $46 \cdot 0$ & $5 \cdot 0$ & $35 \cdot 2$ & $7 \cdot 1$ & $16 \cdot 3$ & 4.9 & $2 \cdot 5$ & 1.0 & 0.17 & 0.07 \\
\hline
\end{tabular}

HOB, heat-treated oat bran; HOE1, HOE2, heat-treated oat outer and inner endosperm respectively; OB, oat bran; OE2, oat inner endosperm; RB, rye bran; RE, rye endosperm; FF, fibre-free.

Mean values were significantly different from those for the FF dietary group: ${ }^{*} P<0 \cdot 05$.

Mean values were significantly different from those for the corresponding bran dietary group: $\dagger P<0-05$.

\pm For details of composition, see Tables 1-3.

$(P=0.000, P=0.000$ and $P=0.000$, respectively), HOE2 $(P=0.000, P=0.000$ and $P=0.000$, respectively), OE2 $(P=0.000, P=0.034$ and $P=0.010$, respectively $)$, and RE $(P=0.000, P=0.006$ and $P=0.002$, respectively; Table 7$)$.

In the animals fed on oat-bran-supplemented diets (HOB and OB) the faecal concentrations of total SpBA were higher than those for the animals fed on the FF $(P=0 \cdot 000)$ and corresponding endosperm-supplemented HOEl $(P=0.000), \operatorname{HOE} 2(P=0.000)$ and OE2 $(P=0.003)$ diets. In the animals fed on the rye-bran diet (RB) it was also higher than that for the animals fed on the FF diet $(P=0.009)$. The concentration of total FBA for the animals fed on heat-treated oat bran (HOB) was higher than that for the animals fed on the FF $(P=0.001)$ and inner endosperm diets (HOE2, $P=0.032)$. No difference was found in the concentration of the total FBA between the animals fed on the heat-untreated bran diets (OB and $\mathrm{RB}$ ) and those fed on the FF and corresponding OE2 and RE diets. The faecal concentrations of TBA were higher in the animals fed on oat-bran diets (HOB and OB) than for the animals fed on the FF ( $P=0.000$ and $P=0.028$, respectively) and corresponding endosperm diets, HOE1 $(P=0.016)$ and HOE2 $(P=0.006)$. No difference was found in the concentration of the TBA between the animals fed on the rye-bran diet (RB) and those fed on the FF and RE diets (Table 7).

The proportion of total SpBA relative to TBA was significantly higher for the animals fed on bran-supplemented diets (means and SD; \%) HOB 11.9 (SD 5.3), OB 11.6 (SD 4.4) and RB 12.6 (SD 7.4), than that for the animals fed on the FF diet, 6.2 (SD 2.8) $(P=0.002$, $P=0.001$ and $P=0.000$ respectively), and the corresponding endosperm-supplemented diets, HOE1 5.0 (SD 2.2) $(P=0.000)$, HOE2 5.9 (SD 1.4) $(P=0.001)$, OE2 5.6 (SD 2.5) $(P=0.000)$ and RE $7.0(\operatorname{SD} 2.6)(P=0.018)$. The proportion of total FBA relative to TBA was significantly lower for the animals fed on bran diets, HOB 88.1 (SD 5.3), OB 88.4 (SD 4.4) and RB 87.4 (SD 7.4), than that for the animals fed on the FF diet, 93.8 (SD 2.8) $(P=0.002$, $P=0.001$ and $P=0.008$, respectively) and endosperm-supplemented diets, HOE1 95.0 
Table 7. Effect of oat and rye fractions on daily excretion and concentration of total saponifiable, total free and total analysed bile acids in faeces of Syrian golden hamsters (Mesocricetus auratus)

Mean values and standard deviations for thirteen hamsters/group)

\begin{tabular}{|c|c|c|c|c|c|c|c|c|c|c|c|c|}
\hline \multirow{3}{*}{$\begin{array}{l}\text { Dietary } \\
\text { group }+\end{array}$} & \multicolumn{6}{|c|}{ Daily bile acid excretion (nmol/d) } & \multicolumn{6}{|c|}{ Bile acid concentration $(\mathrm{nmol} / \mathrm{g})$} \\
\hline & \multicolumn{2}{|c|}{ Saponifiable } & \multicolumn{2}{|c|}{ Free } & \multicolumn{2}{|c|}{ Analysed } & \multicolumn{2}{|c|}{ Saponifiable } & \multicolumn{2}{|c|}{ Free } & \multicolumn{2}{|c|}{ Analysed } \\
\hline & Mean & SD & Mean & SD & Mean & SD & Mean & SD & Mean & SD & Mean & SD \\
\hline $\mathrm{HOB}$ & $253^{*}$ & 124 & $1878^{*}$ & 494 & $2131^{*}$ & 557 & $405^{*}$ & 174 & $3085^{*}$ & 645 & $3490^{*}$ & 670 \\
\hline HOE 1 & $56 \dagger$ & 27 & $1093 \dagger$ & 309 & $1149 \dagger$ & 319 & $136+$ & 63 & 2629 & 731 & $2765+$ & 755 \\
\hline HOE2 & $61 \uparrow$ & 32 & $954 \dagger$ & 339 & $1015 \dagger$ & 367 & $156+$ & 63 & $2481 \dagger$ & 704 & $2637 \dagger$ & 755 \\
\hline OB & $249^{*}$ & 99 & $1936^{*}$ & 61 & $2185^{*}$ & 666 & $338^{*}$ & 131 & 2637 & 749 & $2975^{*}$ & 812 \\
\hline OE2 & $84 \dagger$ & 42 & $1438 * \dagger$ & 517 & $1522 * \dagger$ & 540 & $190^{\dagger}$ & 98 & $3244^{*}$ & 999 & 3434 & 104 \\
\hline RB & $203^{*}$ & 87 & $1665^{*}$ & 771 & $1868^{*}$ & 817 & $247^{*}$ & 108 & 1925 & 729 & 2172 & 762 \\
\hline RE & $70 \dagger$ & 36 & $952 \dagger$ & 361 & $1022 \dagger$ & 379 & 168 & 96 & 2242 & 775 & 2410 & 826 \\
\hline FF & 54 & 39 & 820 & 428 & 874 & 456 & 142 & 77 & 2143 & 649 & 2285 & 686 \\
\hline
\end{tabular}

HOB, heat-treated oat bran; HOE1, HOE2, heat-treated oat outer and inner endosperm respectively; OB, oat bran; OE2, oat inner endosperm; RB, rye bran; RE, rye endosperm; FF, fibre-free.

Mean values were significantly different from those for the FF dietary group: ${ }^{*} P<0.05$.

Mean values were significantly different from those for the corresponding bran dietary group: $\uparrow P<0 \cdot 05$.

$\$$ For details of composition, see Tables $1-3$.

(SD 2.2) $(P=0 \cdot 000)$, HOE2 $94 \cdot 1($ SD 1.4$)(P=0.001)$, OE2 $94.4($ SD $2 \cdot 5)(P=0.000)$ and RE 93.0 (SD 2.6) $(P=0.018)$.

When considering the sub-fractions of the individual bile acids, increased concentrations of saponifiable LCA, epi-deoxycholic acid (EDCA) and DCA were observed in the animals fed on the oat-bran diets (HOB and $\mathrm{OB}$ ) compared with the FF diet (HOB group $P=0.002, P=0.000$ and $P=0.000$, respectively; OB group $P=0.13, P=0.000$ and $P=0.000$, respectively) and corresponding endosperm diets, HOEl $(P=0.001, P=0.000$ and $P=0.000$, respectively), HOE2 $(P=0.002, P=0.000$ and $P=0.000$, respectively $)$, and OE2 $(P=0.009, P=0.006$ and $P=0.018$, respectively). Increased concentrations of saponifiable EDCA and DCA were found in the animals fed on the RB diet compared with the FF diet (Table 8). The concentrations of free LCA in the animals fed on oat-bran diets ( $\mathrm{HOB}$ and $\mathrm{OB}$ ) were unchanged compared with those for the animals fed on the FF diet while the concentration of free LCA in the animals fed on the RB diet was significantly lower than that for the animals fed on the FF $(P=0.002)$ and $\mathrm{RE}(P=0.003)$ diets (Table 9).

A scatter map (Fig. 1) shows the concentration of biliary LCA $v$. daily excretion of faecal saponifiable LCA. In the bran groups ( $\mathrm{HOB}, \mathrm{OB}$ and $\mathrm{RB}$ ) the concentration of biliary LCA was always low ( $\leqslant 0.99 \mathrm{mmol} / \mathrm{l}$, which is the mean value for the endosperm and FF dietary groups). In the endosperm and FF dietary groups the faecal saponifiable LCA was always low ( $\leqslant 74.9 \mathrm{nmol} / \mathrm{d}$, which is the mean value of the bran dietary groups).

\section{$L C A: D C A$ in the bile and in the faeces}

LCD:DCA in the bile of the OB group was lower than that for the FF dietary group $(P=0.035)$, and that for the RB group was lower than those for the RE $(P=0.038)$ and FF $(P=0.010)$ dietary groups (Table 6).

Total LCA (LCA + epi-LCA):total DCA (DCA + epi-DCA) in the faeces of the bran- 
Table 8. Effect of oat and rye fractions on concentration of individual saponifiable bile acids in faeces of Syrian golden hamsters (Mesocricetus auratus)

(Mean values and standard deviations for thirteen hamsters/group)

\begin{tabular}{|c|c|c|c|c|c|c|c|c|c|c|c|c|}
\hline \multirow{3}{*}{$\begin{array}{l}\text { Dietary } \\
\text { group }\end{array}$} & \multicolumn{12}{|c|}{ Concentration of faecal saponifiable bile acid fractions (nmol/g) } \\
\hline & \multicolumn{2}{|c|}{$\begin{array}{c}\text { Epi- } \\
\text { lithocholic }\end{array}$} & \multicolumn{2}{|c|}{ Lithocholic } & \multicolumn{2}{|c|}{$\begin{array}{c}\text { Epi- } \\
\text { deoxycholic }\end{array}$} & \multicolumn{2}{|c|}{ Deoxycholic } & \multicolumn{2}{|c|}{ Chenodeoxycholic } & \multicolumn{2}{|c|}{ Cholic } \\
\hline & Mean & SD & Mean & SD & Mean & SD & Mean & $\mathrm{SD}$ & Mean & SD & Mean & SD \\
\hline HOB & 17 & 7 & $128 *$ & 55 & $25^{*}$ & 15 & $197^{*}$ & 108 & 19 & 8 & $19^{*}$ & 14 \\
\hline HOEl & $8^{* \dagger}$ & 8 & $64 \dagger$ & 28 & $4 \dagger$ & 4 & $51 \dagger$ & 25 & $7 \dagger$ & 7 & $2 \dagger$ & 5 \\
\hline HOE2 & $10+$ & 6 & $69 \dagger$ & 21 & $6 \dagger$ & 6 & $58 \dagger$ & 31 & 14 & 11 & $0^{\dagger}$ & 0 \\
\hline $\mathrm{OB}$ & 13 & 5 & $104^{*}$ & 41 & $20^{*}$ & 12 & $162^{*}$ & 84 & 18 & 7 & $23^{*}$ & 11 \\
\hline OE2 & 9 & 6 & $66+$ & 26 & $8+$ & 7 & $91^{* \dagger}$ & 56 & 11 & 8 & $5 \dagger$ & 7 \\
\hline RB & 10 & 5 & 82 & 39 & $15^{*}$ & 16 & $114^{*}$ & 66 & 13 & 6 & $13^{*}$ & 14 \\
\hline RE & $9^{*}$ & 3 & 67 & 30 & 7 & 6 & 69 & 53 & 12 & 15 & 5 & 7 \\
\hline FF & 14 & 8 & 65 & 32 & 4 & 6 & 43 & 26 & 12 & 11 & 3 & 6 \\
\hline
\end{tabular}

HOB, heat-treated oat bran; HOE1, HOE2, heat-treated oat outer and inner endosperm respectively; OB, oat bran; OE2, oat inner endosperm; RB, rye bran; RE, rye endosperm; FF, fibre-free.

Mean values were significantly different from those for the FF dietary group: $* P<005$.

Mean values were significantly different from those for the corresponding bran dietary group: $\dagger P<0.05$.

$\ddagger$ For details of composition, see Tables 1-3.

Table 9. Effect of oat and rye fractions on concentration of individual free bile acids in faeces of Syrian golden hamsters (Mesocricetus auratus)

(Mean values and standard deviations for thirteen hamsters/group)

\begin{tabular}{|c|c|c|c|c|c|c|c|c|c|c|c|c|}
\hline \multirow{3}{*}{$\begin{array}{l}\text { Dietary } \\
\text { group }\end{array}$} & \multicolumn{12}{|c|}{ Concentration of faecal free bile acid fractions $(\mathrm{nmol} / \mathrm{g})$} \\
\hline & \multicolumn{2}{|c|}{$\begin{array}{l}\text { Epi- } \\
\text { lithocholic }\end{array}$} & \multicolumn{2}{|c|}{ Lithocholic } & \multicolumn{2}{|c|}{$\begin{array}{c}\text { Epi- } \\
\text { deoxycholic }\end{array}$} & \multicolumn{2}{|c|}{ Deoxycholic } & \multicolumn{2}{|c|}{ Chenodeoxycholic } & \multicolumn{2}{|c|}{ Cholic } \\
\hline & Mean & SD & Mean & SD & Mean & SD & Mean & SD & Mean & SD & Mean & SD \\
\hline HOB & 217 & 42 & 1378 & 254 & $128^{*}$ & 45 & $1233^{*}$ & 368 & 58 & 25 & 71 & 78 \\
\hline HOEl & 240 & 96 & 1416 & 450 & $75 \uparrow$ & 40 & $789 * \dagger$ & 223 & 62 & 26 & 46 & 49 \\
\hline HOE2 & 215 & 50 & 1309 & 339 & $80 \dagger$ & 54 & $773^{*}+$ & 363 & 55 & 27 & 51 & 56 \\
\hline $\mathrm{OB}$ & $183^{*}$ & 36 & 1129 & 242 & $109^{*}$ & 52 & $1085^{*}$ & 453 & 63 & 27 & 68 & 61 \\
\hline OE2 & $248 \dagger$ & 73 & $1555 \dagger$ & 474 & 107 & 43 & $1248^{*}$ & 470 & 57 & 14 & 29 & 39 \\
\hline RB & $135^{*}$ & 45 & $849^{*}$ & 284 & $91^{*}$ & 56 & $731^{*}$ & 409 & 56 & 37 & 62 & 58 \\
\hline RE & $213 \dagger$ & 47 & $1229 \uparrow$ & 312 & 62 & 49 & 634 & 387 & 55 & 16 & 48 & 41 \\
\hline $\mathrm{FF}$ & 299 & 157 & 1279 & 336 & 60 & 43 & 396 & 199 & 70 & 18 & 39 & 44 \\
\hline
\end{tabular}

HOB, heat-treated oat bran; HOE1, HOE2, heat-treated oat outer and inner endosperm; OB, oat bran; OE2, oat inner endosperm; RB, rye bran; RE, rye endosperm; FF, fibre-free.

Mean values were significantly different from those for the FF dietary group: ${ }^{*} P<0.05$.

Mean values were significantly different from those for the corresponding bran dietary group: $\dagger P<0 \cdot 05$.

¥ For details of procedures, see Tables $1-3$.

supplemented groups (mean and SD): 1.20 (SD 0.46) for HOB, 1.21 (SD 0.61) for OB and 1.43 (SD 1.06) for RB, were significantly lower than those for the corresponding endospermsupplemented dietary groups: 1.93 (SD 0.51$)$ for HOEl $(P=0.001), 2.05$ (SD 0.74) for HOE2 $(P=0.002)$ and 2.35 (SD 0.75) for RE $(P=0.017)$, and the FF dietary group 3.67 (SD 1.08$)$ 


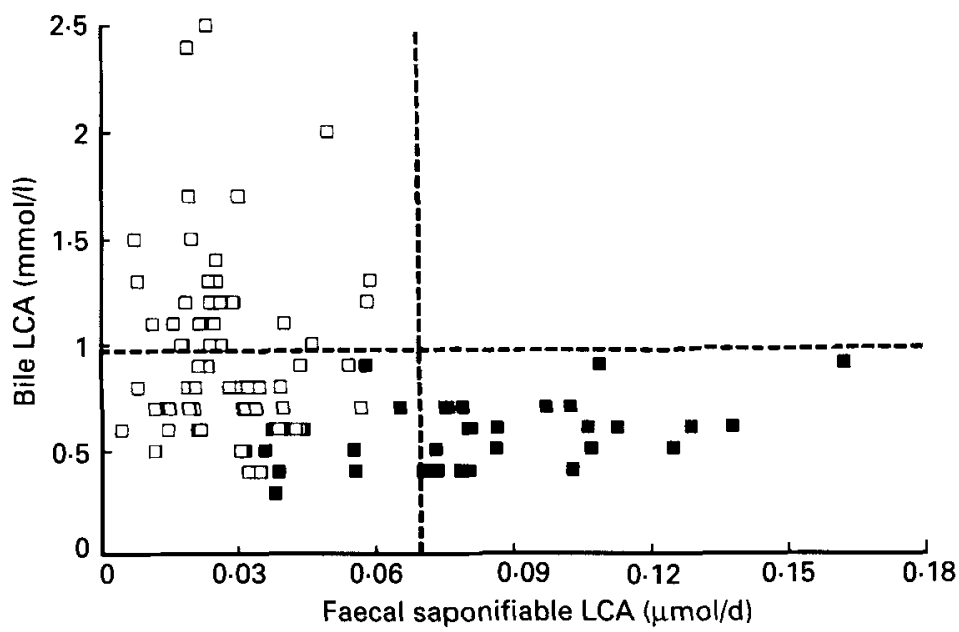

Fig. 1. Scatter map of the concentration of biliary lithocholic acid (LCA) $v$ daily excretion of faecal saponifiable LCA for all experimental groups of Syrian golden hamsters (Mesocricetus auratus) fed on oat and rye fractions. ( $\square$ ), low-fibre and fibre-free dietary groups; ( $\square$ ), high-fibre dietary groups. (---), The mean concentration of biliary LCA in the low-fibre dietary groups; (:) the mean daily excretion of faecal saponifiable LCA in the high-fibre dietary groups. For details of diets and their composition, see Tables 1-3.

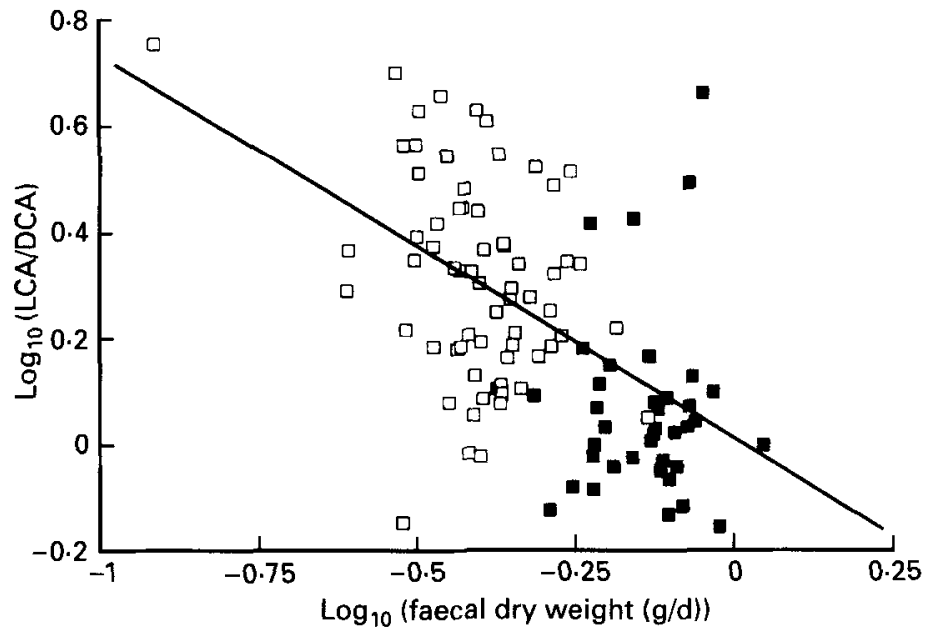

Fig. 2. The relationship between $\log _{10}$ total lithocholic acid (LCA): total deoxycholic acid (DCA) and $\log _{10}$ faecal dry weight in faeces from Syrian golden hamsters (Mesocricetus auratus) fed on oat and rye fractions ( $\square$ ), lowfibre and fibre-free dietary groups; $(\square)$, high-fibre dietary groups. For details of diets and their composition, see Tables 1-3.

$(P=0.000$ respectively). However, there was no difference between the OB and OE2 1.32 (SD 0.23) dietary groups. The ratios for all endosperm-supplemented groups were also significantly lower than those for the FF dietary groups (HOE1, HOE2 and OE2 $P=0 \cdot 000$; RE $P=0.001$ ).

LCA:DCA for bile was positively correlated with that for faeces $(r 0.33, P<0.001$, $n$ 104). The faecal $\log _{10}$ total LCA: total DCA was negatively well correlated with $\log _{10}$ faecal dry weight (Fig. $2 ; r-0.54, P<0.001, n 104$ ). 


\section{DISCUSSION}

Oats have recently received increased attention from the nutrition and medical communities because of their dietary fibre content and role in reducing blood cholesterol levels, a recognized risk factor for coronary heart disease. Although the mechanism(s) for the hypocholesterolaemic effect of oats is not clear, an increase in faecal excretion of bile acids (Judd \& Truswell, 1981; Illman \& Topping, 1985; Zhang et al. 1992) by oat fibre, mainly the mixed-linked $\beta$-glucans, is supposed to contribute to the effect (Henry, 1987; Shinnick et al. 1988).

Attention has also been paid to the increased faecal excretion of bile acids after intake of oats, because bile acids and their derivatives from bacterial fermentation have been suggested to act as carcinogens (Turjman et al. 1984; Owen et al. 1987; Nair, 1988). An increased proportion of secondary bile acids might increase the risk of colo-rectal cancer (Mullan et al. 1990) and faecal LCA : DCA may be an important aetiological factor in colorectal cancer (Owen et al. 1983).

The present study shows that the bran diets increased both the daily faecal excretion of bile acids and faecal weight. As a result of the dilution effect of the increased faecal weight induced by the different bran diets, the concentrations of TBA were unchanged in the animals fed on the RB diet (Table 7). The concentration of FBA was unchanged in the animals fed on unsteamed flaked oat-bran and RB diets. The concentration of free LCA and ELCA was reduced in the animals fed on unsteamed flaked oat-bran and RB diets (Table 9), while the bran groups had an increased concentration of free DCA and EDCA compared with the groups fed on the FF diet. The difference in concentrations of faecal free LCA and FBA between the animals fed on steamed flaked and unsteamed flaked oat-bran diets suggested that the altered physical state of oats produced by heating may have slightly changed the physiological effects. Dietary fibre, its dilution effects and binding of bile acids have been suggested to prevent the carcinogenesis of the colon (Jenkins et al. 1986; Kritchevsky, 1986; Greenwald et al. 1987).

The conjugated bile acids secreted from the liver undergo deconjugation when passing to the large intestine. Part of the deconjugated bile acids, free bile acids, are esterified in the large intestine to form saponifiable derivatives, for example $\mathrm{C}_{24}$ carboxyl esters or fatty acyl esters (Norman, 1964; Kelsey \& Sexton, 1976). The biological importance of the SpBA is not clear. The present experiment showed that both oat and rye bran increased the daily faecal excretion and the concentration of faecal SpBA. The concentration of biliary LCA $v$. the daily excretion of faecal saponifiable LCA from all individual animals is shown in Fig. 1. When the high-fibre dietary groups were separated from the low-fibre groups in the scatter map the concentrations of biliary LCA in all the animals in the HFD groups were low, while the daily excretion of saponifiable LCA in all the animals in the LFD or FF groups was low. The results strongly suggest that the absorption of LCA from the large intestine, which is related to the biliary concentration of LCA, was directly associated with the fibre content in the diet, and that the esterification of bile acids was also influenced by the dietary fibre. The free secondary bile acids, especially free LCA, are thought to be toxic and carcinogenic to the colonic mucosa (Rafter et al. 1987), and thus the colonic mucosa of many animals in the LFD groups is obviously more exposed to the free LCA. The SpBA fraction accounts for $5-10 \%$ of the total bile acids. The characteristics and the biological importance of this bile acid fraction should be studied further.

The faecal LCA:DCA values for both bran- and endosperm-supplemented dietary groups are much lower than that for the FF dietary group. The lowest faecal LCA:DCA values were obtained with the bran-supplemented HFD groups. The correlation between the biliary and faecal LCA:DCA values indicated the logical relationship between the 
faecal and biliary bile acids. LCA:DCA has been suggested to be an indicator for the risk of colo-rectal cancer in humans (Owen et al. 1983). It has been observed in humans that there is a significant regression for $\log _{10} \mathrm{LCA}: \mathrm{DCA} v . \log _{10}$ stool weight (Brydon et al. 1988). In the present animal experiment we observed a similar result; $\log _{10}$ LCA(total): DCA(total) was well correlated with $\log _{10}$ faecal dry weight (Fig. 2). The results from HFD groups were located at the lower-right section of the map with a few exceptions, while the results from LFD groups were mostly found at the upper-left section of the map.

In conclusion, oat and rye bran intake increased the faecal weight and the daily excretion of total bile acids in hamsters. Oat and rye bran intake reduced the concentration of LCA in the bile. The reduced concentration of biliary LCA could be related to a decreased concentration of free LCA in the large intestine. Both bran and endosperm diets reduced the faecal LCA:DCA value compared with a fibre-free diet.

This study was supported by grants from the Swedish Board of Technical Development (STU); Swedish Council of Forestry and Agricultural Research (SJFR); Umeå Cancer Research Foundation of the Department of Oncology, University of Umeå; Wasabröd AB, Filipstad, Sweden; the Sigrid Jusélius Foundation; and the Medical Research Council of the Academy of Finland, Helsinki, Finland. The authors especially thank Mr Roger Andersson for excellent analytical work on bile acids, and Mr Sören Holmgren, Ms Ann-Marie Åhrén, Ms Ulla-Stina Kågström and Mrs Aila Heikkinen for their technical assistance.

\section{REFERENCES}

Åman, P. \& Graham, H. (1987). Analysis of total and insoluble mixed-linked $(1 \rightarrow 3),(1 \rightarrow 4)-\beta$-D-glucans in barley and oats. Journal of Agricultural and Food Chemistry 35, $704-709$.

Anderson, J. W., Spencer, D. B., Hamilton, C., Smith, S. F., Tietyen, J., Bryant, C. A. \& Oeltgen, P. (1990). Oatbran cereal lowers serum total and LDL cholesterol in hypercholesterolemic men. American Journal of Clinical Nutrition 52, 495-499.

Anon (1984). Determination of crude oils and fats. Official Joumal of the European Communities L15, $29-30$.

Association of Official Analytical Chemists (1990). Official Methods of Analysis. vol. 1. Agricultural Chemicals; Contaminants; Drugs, 15th ed, pp. 70, 74. Washington DC: Association of Official Analytical Chemists.

Bosaeus, I., Carlsson, N. G. \& Andersson, H. (1986). Low-fat versus medium fat enteral diets. Scandinavian Journal of Gastroenterology 21, 891-896.

Brydon, W. G., Eastwood, M. A. \& Elton, R. A. (1988). The relationship between stool weight and the lithocholate/deoxycholate ratio in faeces. British Journal of Cancer 57, 635-636.

Chen, W.-J. L. \& Anderson, J. W. (1981). Effects of oat bran, oat gum and pectin on lipid metabolism of cholesterol-fed rats. Nutrition Reports International 24, 1093-1098.

Gold, K. V. \& Davidson, D. M. (1988). Oat bran as a cholesterol-reducing adjunct in a young, healthy population. Western Journal of Medicine 148, 299-302.

Greenwald, P., Lanza, E. \& Eddy, G. A. (1987). Dietary fibre in the reduction of colon cancer risk. Journal of The American Dietetic Association 87, 1178-1188.

Henry, R. J. (1987). Pentosan and (1-3),(1-4)- $\beta$-glucan concentrations in endosperm and whole grain of wheat, barley, oats, and rye. Journal of Cereal Science 6, 253-258.

Hurt, H. D., Mathews, R. \& Ink, S. (1988). Biological Considerations of Oat Dietary Fibre and Beta-glucans. Proceedings of 3rd International Oat Conference, Lund, Sweden, pp. 10-12.

Illman, R. J. \& Topping, D. L. (1985). Effect of dietary oat bran on faecal steroid excretion, plasma volatile fatty acids and lipid synthesis in rats. Nutrition Research 5, 839-846.

Jenkins, D. J. A., Jenkins, A. L., Rao, A. V. \& Thompson, L. U. (1986). Cancer risk: Possible protective role of high carbohydrate high fiber diets. American Journal of Gastroenterology 81, 931-935.

Judd, P. A. \& Truswell, A. S. (1981). The effect of rolled oats on blood lipids and fecal steroid excretion in man. American Journal of Clinical Nutrition 34, 2061-2067.

Kelsey, M. I. \& Sexton, S. A. (1976). The biosynthesis of ethyl esters of lithocholic acid and isolithocholic acid by rat intestinal microflora. Journal of Steroid Biochemistry 7, 641-647.

Korpela, J. T., Adlercreutz, H. \& Turunen, M. J. (1988). Fecal free and conjugated bile acids and neutral sterols in vegetarians, omnivores, and patients with colorectal cancer. Scandinavian Journal of Gastroenterology 23, $277-283$

Korpela, J. T., Fotsis, T. \& Adlercreutz, H. (1986). Multicomponent analysis of bile acids in faeces by anion 
exchange and capillary column gas-liquid chromatography: Application in oxytetracycline treated subjects. Journal of Steroid Biochemistry 25, 277-284.

Korpela, J. T., Korpela, R. \& Adlercreutz, H. (1992). Fecal bile acid metabolic pattern after administration of different types of bread. Gastroenterology 103, 1246-1253.

Kritchevsky, D. (1986). Diet, nutrition and cancer. The role of fibre. Cancer 58, 1830-1836.

Mullan, F. J., Wilson, H. K., Majury, C. W., Mills, J. O. M., Cromie, A. J., Campbell, G. R. \& McKelvey, S. T. D. (1990). Bile acids and the increased risk of colorectal tumours after truncal vagotomy. British Journal of Surgery 77, 1085-1090.

Nair, P. P. (1988). Role of bile acids and neutral sterols in carcinogenesis. American Journal of Clinical Nutrition 48, 768-774.

Norman, A. (1964). Faecal excretion products of cholic acid in man. British Journal of Nutrition 18, 173-186.

Owen, R. W., Dodo, M., Thompson, M. H. \& Hill, M. J. (1983). The faecal ratio of lithocholic acid to deoxycholic acid may be an important aetiological factor in colorectal cancer. European Journal of Cancer and Clinical Oncology 19, 1307.

Owen, R. W., Dodo, M., Thompson, M. H. \& Hill, M. J. (1987). Fecal steroid and colorectal cancer. Nutrition and Cancer 9, 74-80.

Qureshi, A. A., Chaudhary, V., Weber, F. E., Chicoye, E. \& Qureshi, N. (1991). Effects of brewer's grain and other cereals on lipid metabolism in chickens. Nutrition Research 11, 159-168.

Rafter, J., Geltner, U. \& Bruce, R. (1987). Cellular toxicity of human faecal water - possible role in aetiology of colon cancer. Scandinavian Journal of Gastroenterology 22 (Suppl. 129), 245-250.

Shaw, R. \& Elliott, W. H. (1978). Bile acids. LV. 2,2-dimethoxypropane: an esterifying agent preferred to diazomethane for chenodeoxycholic acid. Journal of Lipid Research 19, 783-787.

Shinnick, F. L., Longacre, M. L., Ink, S. L. \& Marlett, J. A. (1988). Oat fibre: Composition versus physiological function in rats. Journal of Nutrition 118, 144-151.

Theander, O. \& Westerlund, E. (1986). Studies on dietary fiber. 3. Improved procedures for analysis of dietary fiber. Journal of Agricultural and Food Chemistry 34, 330-336.

Turjman, N., Goodman, G. T., Jaeger, B. \& Nair, P. P. (1984). Diet, nutrition intake, and metabolism in populations at high and low risk for colon cancer. Metabolism of bile acids. American Journal of Clinical Nutrition 40, 937-941.

Westerlund, E., Andersson, R. \& Åman, P. (1993). Isolation and chemical characterisation of water-soluble mixed-linked $\beta$-glucans and arabinoxylans in oat milling fractions. Carbohydrate Polymers 20, 115-124.

Zhang, J. X., Hallmans, G., Andersson, H., Bosaeus, I., Aman, P., Tidehag, P., Stenling, R., Lundin, E. \& Dahlgren, S. (1992). Effect of oat bran on plasma cholesterol and bile acid excretion in nine subjects with ileostomies. American Journal of Clinical Nutrition 56, 99-105. 